\title{
VALORES DE LA SOCIEDAD MODERNA: UNA VISIÓN DEL CAMBIO SOCIAL
}

\author{
E. Duque* \\ Faculdade de Filosofia e Ciências Sociais da Universidade Católica Portuguesa \\ Centro de Estudos de Comunicação e Sociedade - Universidade do Minho \\ eduardoduque@braga.ucp.pt* \\ Submetido 02/02/2017 - Aceito 19/05/2017 \\ DOI: $10.15628 /$ holos. 2017.5600
}

\section{RESUMO}

Las sociedades tradicionales se caracterizan por el predominio de visiones religiosas del mundo en contrapunto con las sociedades modernas, lo que abre otras vías de sentido, además de la expresión religiosa. Con este estudio se pretende conocer la influencia de los valores de las sociedades modernas en los cambios religiosos, entre 90 y 2000. Lo hacemos recorriendo a los datos de la Encuesta de los Valores Europeos para 8 países de tradición católica. El cuestionario del EVS contempla una serie de orientaciones en diversos ámbitos de la vida. Se han construido varias escalas con la pretensión de presentar las orientaciones de valor. En nuestro análisis hemos seleccionado dos constructos: recorriendo a la tesis de Inglehart, que nos permite explicar el cambio de valores, y a la batería de preguntas de Rokeach para determinar los valores que los individuos consideran esenciales para la vida. Los resultados nos han permitido concluir que estamos asistiendo a una reconfiguración de la mentalidad que tiene como sujeto determinante las generaciones más jóvenes que asimilaron los valores de la independencia y determinación y los valores del bienestar y autorealización, una vez que su contexto socio-cultural y económico les fue favorable.

PALAVRAS-CHAVE: Valores, modernidad, cambio social, individualización, religión.

\section{VALUES OF MODERN SOCIETY: A VISION OF SOCIAL CHANGE}

\begin{abstract}
Traditional societies are characterized by the predominance of religious worldviews, in contrast to modern societies, which open up other avenues of sense, besides religious expression. This study aims to determine the influence of the values of modern societies on religious changes, between 1990 and 2000. We have recourse to data from the European Values Survey for eight Catholic countries. The EVS questionnaire provides a set of guidelines in various areas of life. Several scales have been built with the aim of presenting value orientations. In our analysis we
\end{abstract}

selected two constructs: following Inglehart's thesis, which enables us to explain the change in values, and the Rokeach set of questions to determine the values that individuals considered essential for life.

The results allowed us to conclude that we are witnessing a reconfiguration of the mindset that has a decisive influence on younger generations who have assimilated the values of independence and determination and the values of welfare and selfrealization, once the socio-cultural and economic context was favourable.

KEYWORDS: Values, modernity, social change, individualization, religion. 


\section{INTRODUCCIÓN}

No se trata en este momento de enzarzarnos en una discusión acerca del camino de nuestra cultura o sociedad. Pero se comprenderá mejor desde esta perspectiva que las sociedades industriales avanzadas han conocido un proceso de convergencia cultural marcado por dos fuertes tendencias que creemos inseparables: por un lado, por la creciente autonomización individual (Ester, Halman y De Moor, 1994); por otro lado, según la tesis de Inglehart, por la emergencia de la ascensión de los valores postmaterialistas, los cuáles alcanzan sobre todo a las generaciones más jóvenes, con más estudios y de los medios sociales de nivel socioeconómico alto.

Creemos que ambas tesis son inseparables porque si la hipótesis de la individualización es correcta, cabría esperar una sociedad moderna que se define no sólo por la autonomía personal sino por la búsqueda de la autorrealización y como postula Inglehart, ambas características autonomía y autorrealización - expresan valores típicamente postmaterialistas, propios de las sociedades avanzadas, basadas más en ideas de autorrealización y participación (postmaterialismo) que de supervivencia y bienestar económico (materialismo).

Estos cambios, según Inglehart, están vinculados a la necesidad de seguridad (1977: 21 y ss) que, en las sociedades tradicionales, ha sido suministrada sobre todo por la religión y por las normas culturales rígidas. Paradójicamente a estas sociedades (materialistas), en las sociedades más desarrolladas, de valores predominantemente postmaterialistas, se espera no sólo una remodelación socio-cultural, sino también una metamorfosis de la dimensión valorativa. En este contexto, se parte del enfoque de que los cambios que se han producido en el sistema sociocultural han llevado a cambios individuales que, a su vez, tuvieron repercusiones en la estructura social y, consecuentemente, en las expresiones valorativas.

Para nuestro propósito, más importante que mostrar el proceso histórico de cómo se ha llegado a la autonomización del individuo - para lo cual necesitaríamos retroceder hasta finales de los años sesenta y primeros de los setenta para comprender el cambio de los comportamientos (Durán Vázquez y Duque, 2017; Houellebecq, 1999: 50) - es fijar la atención en la forma como el proceso de la individualización se está desarrollando y ganando espacio en las sociedades más avanzadas bien como en las generaciones más jóvenes.

\section{EL NUESTRO MOMENTO TARDOMODERNO}

El hombre de la modernidad ha depositado su fe y confianza en la razón, como si ésta le disipase las dudas, le aportase certezas, le apuntase sentidos para su trayecto y le trajese confort eterno. Ortega y Gasset era bien consciente de esta realidad, cuando consideró que el gran problema de la generación ha despertado porque los hombres "vivieron de la fe en la razón" (1981: 16). Pero, por lo que se ha visto en la historia, la razón también sufre cambios, no es distinta de otras estructuras, ni propiedad de un saber, sino que es, en definitiva, el principio más radical de la modernidad. Como subraya Cassirer, la razón "ha perdido para nosotros su simplicidad y su significación unívoca" (1984: 20).

Pasamos de una razón geométrica (Heidegger, 1967: 110), que se auto-concibe como absoluta, con poder creador, a una razón dialéctica (Sichirollo, 1976: 177); de una razón rigurosa y unitaria (Hobbes y Spinoza), a una débil (Vattimo y Rovatti, 1983: 14) y fragmentaria (Lyotard, 1983: 36 y 78). Consecuentemente, si es débil ha dejado de ser razón y por eso se asiste a una dimensión de la razón fragmentada y sinrazón, en cuyo caso no sirve para nada. De esta racionalidad autónoma y frágil surge una visión diferenciada del mundo, dónde proliferan las 
"dimensiones de razón" (Habermas, 1999: 202) y dónde se ha dividido la misma razón y la sociedad en una pluralidad weberiana de "esferas de valores" (1964). Habermas reconoce que Weber comprueba "cómo los subsistemas de acción racional con arreglo a fines se desgajan de sus fundamentos racionales con arreglo a valores y se independizan siguiendo su propia lógica" (Habermas, 1989: 305), es decir, en realidad, que a partir de ahora, "las estructuras de conciencia se diferencian, formando esferas culturales de valor de carácter autónomo, diferenciación que se traduce en un antagonismo de los correspondientes órdenes de la vida" (Habermas, 1989: 305 y ss).

Ante de una razón fragmentada, y ahora descentrada, se sigue la disociación de los saberes, como que se trate de colocar en dimensiones distintas el arte, las ciencias exactas o las filosofías. Pero, a añadir a esta diversificación de las razones, hay una cada vez más especialización de las materias, lo que produce, en una expresión de Habermas (1991: 78) a comentar lo que Weber caracteriza como distintivo del racionalismo occidental, "una cultura de expertos". Esta razón y esta cultura han llevado ya no solamente a la fragmentación de la razón, sino a la fragmentación del propio mundo. Así, en un raciocinio nomotético, se desprende que de una razón fragmentada, esto es, que no da ninguna garantía - relativa si quisiéramos - no se espera nada y tampoco respuestas para los interrogantes sociales y morales, tornándose, por extensión, una razón sin esperanza (Quintanilla, 1981: 17). Llegamos, así, a una situación de crisis de la propia racionalidad y, como consecuencia, de la verdad, del sujeto y, hasta, de la misma historia y de la propia humanidad. Ahora la razón como proyecto del sujeto por una vida emancipada de conexiones, es la medida única de todas las cosas.

Este tipo de racionalidad científico-técnica es una de las tesis sociológicas fundamentales de la modernidad y sobre ella discurren distintos pensadores, tanto teóricos como críticos (Beck, 2007: 3-24; Escobar, 2012; Mc Carthy, 1998:43; Osorio, 2015: 213-252; Weber, 1983: 11) en la medida en que transforma profundamente la forma de pensar, de pensarse y relacionarse.

\subsection{DEL INDIVIDUALISMO A LA INDIVIDUALIZACIÓN}

La creencia en el metarrelato del progreso científico-técnico ha generado muchas actitudes. El individualismo fue una de ellas. El perfeccionamiento de la racionalidad técnica, con su corolario en el avance de las tecnologías de la información, forjó una nueva sociedad, a la que el sociólogo Manuel Castells llamó "sociedad red" (Castells, 2000), que, estrechando fronteras, conduce también a una gran individualización: "nuestras sociedades se estructuran cada vez más en torno a una oposición bipolar entre la red y el yo" (Castells, 2000: 33). Esta racionalidad técnica, forjada en el capitalismo, destruye, o por lo menos transfigura, la naturaleza relacional del individuo, en la medida en que lo remite hacia la esfera de lo privado, no sólo en el campo sociológico sino en todos los ámbitos, exaltando el individuo mismo, que, al final, será llevado a una forma de vivir solipsista de que habla Lipovetsky en La Era del Vacío (1983: 7), o de incertidumbre de R. Rorty (1984: 38).

De este modo, el individualismo aboga por la satisfacción de sus preferencias y la libertad de elegir (Nevite, 2006: 100-102); rechaza totalmente el carácter social del ser humano y su tendencia relacional; abre puertas al subjetivismo, colocando el propio individuo como creador del objeto, impugnándole su autonomía ontológica; impone una mentalidad empírica, experimental y práctica; en el fondo, el individualismo da lugar a una visión de la sociedad de "tipo mecanicista" que concibe la sociedad como simple conjunto de individuos, descentrándolos y automatizándolos. 
El hombre individualista, en el decir de Mardones "orientado al dominio del mundo, con un estilo de pensamiento formal y una mentalidad funcional" (1988: 31), ha creado, en su comodidad egocéntrica, la "dictadura del aparato" de Jaspers o la "megamáquina" de Fromm, que no pasan de "borregos laboriosos" de Steven Lukes, enterrados en una "razón instrumental" (Horkheimer). En definitiva, esta configuración social funcional fabricó una nueva identidad, un nuevo tempo y una nueva velocidad, como que todo se logre con el "clicar" de un botón, como ha pretendido la Kodak al anunciar: "Usted oprime el botón, nosotros hacemos lo demás". Esta fotografía del mundo, colorida por millones de botones y tejida con los hilos del individualismo pragmático, ha dejado de ser negro y blanco, para convertirse en apolítica y amoral. Esta nueva visión del mundo es la consecuencia del creciente proceso de individualización que se presenta como un concepto demasiado complejo para ser definido, como comúnmente se hace, por expresiones como: "fragmentación", "flexibilización", "autonomía”, "ensimismación" y muchos otros conceptos que, por más expresivos que sean, no representan más que una dimensión del proceso de la individualización.

En este contexto encontramos las aportaciones destacadas desde diversas corrientes: desde las funcionalistas lideradas por Parsons; de los interaccionistas simbólicos de la escuela de Chicago; de la crítica de Homans a Parsons desde el reduccionismo individualista (Homans, in Giddens, 1991: 81-112); desde la disputa sobre el positivismo en la década del 60 y 70 entre Adorno y Popper (Adorno et al, 1973), así como la discusión entre Luhmann y Habermas en la década del 70 (Habermas, 1988: 309-419). Todos ellos se refieren a la dialéctica entre sociedad e individuo.

Con las contribuciones de Beck y Giddens, la temática de la individualización fue substancialmente modificada, principalmente con el abordaje del concepto de modernización reflexiva (Beck, in Beck, Giddens y Lash, 1997: 13-74), proponiendo una radical revisión de la dialéctica individuo/sociedad. De este modo, la individualización y la globalización surgen como dos caras del mismo proceso de modernización reflexiva. Según Beck (1998), en las sociedades diferenciadas, lo que se ha incrementado es la separación y la diferenciación de las personas en sus relaciones mutuas, dando lugar a un proceso de individualización que, sin embargo, se encuentra estrechamente ligado al proceso civilizatorio.

Para Manuel Castells (2000) este proceso se explica a partir de la individualización del trabajo. Según este autor, la economía moderna se estructura en torno a redes globales de capital, gestión e información y el acceso al conocimiento tecnológico que constituye la base de la productividad y la competencia. En este contexto el trabajo es cada vez más individualizado, perdiendo su identidad colectiva. Por eso, refiere Castells que las sociedades se estructuran cada vez más en torno a una posición bipolar entre la red y el yo, donde las redes globales de intercambios instrumentales conectan o desconectan, de forma selectiva, individuos, grupos, regiones o incluso países según su importancia para cumplir las metas procesadas en la red, fragmentando, de este modo, los movimientos sociales (Bescansa, 2011; Conover, Ferrara, Menczer y Flammini, 2013; Cotarelo, 2013; Imbert, 2011; Prensky, 2011).

A esta realidad no es ajeno A. Touraine (1998), que subsidia este tema refiriendo que la individualización se dirige a un nuevo modo de socialización, a un cambio de forma en la relación entre individuo y sociedad, donde las crisis sociales son vividas como crisis individuales, produciéndose, a su vez, la desinstitucionalización, entendida, esta, como el debilitamiento o la desaparición de normas codificadas.

Por nuestra parte, recurrimos a la definición de individualización de Loek Halman que incluye en su definición de individualización los siguientes aspectos: i) un aumento de la autonomía de los individuos en el desarrollo de sus propios valores y normas que 
progresivamente se desvían del sistema tradicional de valores institucionalizados. ii) De este modo, la autorrealización y la felicidad personal han pasado a ser el corazón del desarrollo de valores y de la selección de las normas. iii) La individualización es el proceso social e histórico en el cual los valores, creencias, actitudes y conductas se basan progresivamente en la elección personal y dependen menos de la tradición y de las instituciones sociales y su control social (Duque, 2013: 82-83; Ester, Halman y De Moor, 1994: 7; Halman, 1995: 419-439).

Este mismo autor, al analizar los resultados del EVS del 90, refiere que las personas están cada vez más inclinadas a rechazar la autoridad tradicional, fenómeno que es visible en el enfriamiento del grado de confianza sobre las instituciones. Este aspecto, que se puede traducir por una mayor autonomía y emancipación del sujeto, lleva, al decir de Halman (2003: 257), a una desintegración tanto institucional como social. De este modo, se comprende que las sociedades modernas caminen progresivamente hacia la adhesión a los valores individualistas en detrimento de valores tradicionales.

En Portugal, Jorge Vala analiza esta misma dimensión de la individualización, a través de una pregunta del EVS de 90, a partir de la cual se diagnostica las orientaciones deseadas en la vida pública y privada, construyendo dos niveles en que se manifiestan por un lado los valores del tradicionalismo y, por otro lado, los valores de la modernidad. La modernidad remite hacia la individualización de la vida social, que va acompañada por una menor expresión de los valores de sumisión y de una posición más crítica ante las instituciones de regulación social. Por otro lado, el tradicionalismo añade la importancia de la familia, de una vida más simple y de la autoridad. Estos resultados fueron obtenidos a través de un análisis factorial de componentes principales (Vala, 1993: 234-35).

De este análisis se concluyó que la modernidad está sobre todo asociada a las edades más jóvenes y a los grados de instrucción más elevados. Todavía, en Portugal es más valorada la autoridad y menos el desarrollo de los valores individuales que en los demás países europeos (Vala, 1993: 235-36).

\subsection{MATERIALISMO, POSTMATERIALISMO}

Inglehart recurre a la teoría del materialismo-postmaterialismo para explicar el cambio de valores. Lo hace, transponiendo en el orden social la jerarquía de motivaciones que Abraham Maslow (1954) postula para el nivel personal, señalando que las sociedades tenderán motivaciones de orden superior (de necesidades no fisiológicas como estima, auto expresión y satisfacción estética) cuando tengan resueltas las necesidades de orden inferior (el mantenimiento económico y la seguridad física).

Así, las sociedades postmaterialistas irrumpen después de las materialistas, siendo, su adviento visto como fruto del resultado del aumento general de la seguridad física y del crecimiento económico (esta refleja la hipótesis de la "escasez") (cf.: Gil Roales-Nieto, 2009; Inglehart, 1977: 21 y ss). Según esta hipótesis "las prioridades de un individuo reflejan su medio socio económico: uno pone mayor valor subjetivo en aquellas cosas que son relativamente escasas" (Inglehart, 1977: 33).

De este modo, los dos indicadores - seguridad física e económica - se tornan responsables por las orientaciones valorativas de las sociedades; siendo, todavía, el económico el más preponderante: la escasez económica genera inseguridad $y$, para superarla, se requiere prioridades materialistas, mientras que el confort económico produce seguridad y, por tanto, favorece el desarrollo de valores postmaterialistas. Estos valores, a su vez, parecen ser los más difundidos entre las generaciones más jóvenes, una vez que éstas fueran educadas en un 
ambiente de mayor seguridad personal y económica (en el pos-guerra), admitiéndose, así, la hipótesis de la socialización, que explica que el cambio de valores hacia una orientación postmaterialista será, sobre todo, un "cambio generacional". Todavía, es posible especificar otra componente del cambio hacia los valores postmaterialistas que dice respecto a cambios coyunturales en el curto plazo, como los períodos breves de recesión económica, que afectarán de forma similar a todas las generaciones, tratándose, de esta forma, de cambios que se deben a un "efecto de período".

Así siendo, la hipótesis de la escasez se complementa con la hipótesis de la socialización: "la relación entre el medio socio económico y las prioridades valorativas no es directa: existe una brecha temporal sustantiva porque los valores básicos de una persona reflejan las condiciones que prevalecieron en los años de juventud" (Inglehart, 1977: 33).

De otra forma, se puede decir que las sociedades actuales del occidente - puesto que han dejado de tener como preocupación esencial la seguridad física y económica (características de las sociedades materialistas) - han proporcionado a los individuos otras necesidades "no materialistas", basadas más en ideas de autorrealización y participación, como el sentimiento de pertenencia o de identidad, de estima o de afecto, de expresión individual o de preferencia por valores estéticos (Inglehart, 1977). En una lectura complementaria, cuanto mayor es el desarrollo socio-cultural de un país, mayor será la expresión de los valores postmaterialistas relativos a los materialistas.

Esta tesis fue comprobada empíricamente tanto por el propio Inglehart (1971, 1977, 1985, 1990 y 1997), como por otros estudiosos: Abramson e Inglehart, 1992; Díez Nicolás, 1994 y 1995; Gil Roales-Nieto y Segura, 2010, entre otros, mostrando, por un lado, la tendencia de las sociedades, económicamente más seguras, hacia valores postmaterialistas (hipótesis de la escasez); por otro lado, y en la medida en que los individuos adquieren la mayor parte de sus valores básicos durante la adolescencia, el postmaterialismo debería estar inversamente relacionado con la edad, una vez que esos valores son los que perduran durante largos períodos de tiempo en sus vidas (hipótesis de la socialización) (Orizo y Elzo, 2000: 292-293).

Desde el punto de vista empírico, las pruebas de resistencia de la teoría del materialismo y postmaterialismo fueron inicialmente testadas a través de los Eurobarómetros y de otros estudios de la entonces Comunidad Económica Europea sobre los países constituyentes de la CEE (Inglehart, 1971, 1976 y 1977), después a partir del European Values Surveys (EVS) de 1981 (que incluía 26 países), de 1990 (países europeos y no europeos) y de 1999 (que incluía 32 países), más tarde, a través de la World Values Surveys (WVS) de 1990, 1995 y 2000 que abarca ya más del $75 \%$ de la población mundial.

A partir de estas bases de datos y de los estudios que citamos, son muchas las investigaciones que coinciden en mostrar un doble proceso del cambio en el sistema de valores de las sociedades:

i) desde los valores materialistas (valores de escasez o de supervivencia) a los postmaterialistas (valores de auto-expresión);

ii) desde los valores tradicionales a los secular-racionales.

A estos dos ejes valorativos corresponden, por un lado, a actitudes de respeto por la autoridad (sociedad materialista), por otro, a actitudes de libre elección (sociedad postmaterialista).

La tesis de materialismo y postmaterialismo de Inglehart - que mide, a través de sus indicadores concretos, el cambio de forma sistematizada y comparable - se presenta de extrema 
utilidad en la medida en que explica el cambio de valores en los procesos de modernización y postmodernización que se han producido y se continúan produciendo en las sociedades.

\subsection{HIPÓTESIS DE TRABAJO}

De acuerdo con estas perspectivas y enfoques que tratan de poner en relación la individualización y el materialismo/postmaterialismo, es posible establecer algunas hipótesis al respecto, partiendo de datos empíricos, que se encuentran en las encuestas del EVS de 1990 e 2000, para su posterior verificación.

Más específicamente puede esperarse la confirmación de las siguientes hipótesis:

1- El proceso de la individualización se debe a efectos generacionales y no a efectos de ciclo de vida;

2- Cuanto mayor es la adhesión a los valores postmaterialistas mayor es la aceptación de los valores más orientados hacia el individualismo, mientras que la adhesión a los valores materialistas será mayor entre los individuos que asumen valores más tradicionales.

\section{METOdOLOGÍA}

A fin de conseguir un abordaje más completo del cambio del patrón valorativo, procederemos a un análisis comparativo de este fenómeno entre Portugal y 7 países europeos: Austria, Bélgica, Francia, Irlanda, Italia, Polonia y España.

El argumento que ha predominado en la selección de los países con que se compara la situación del cambio social portugués fue la matriz histórico-religiosa que los países comparten, a pesar de expresar dos diferentes realidades religiosas: por un lado, los países que a semejanza de Portugal mantienen porcentajes de católicos aún elevadas, como Irlanda, Polonia e Italia; por otro lado, países que presentan un mayor grado de secularización, como Francia, Bélgica, Austria y España. Esta comparación es posible ya que se trata de una misma investigación con el recurso de los mismos instrumentos y métodos de análisis en las sociedades en causa.

De forma a captar los cambios en las mentalidades bien como las formas de valores que les está subyacente, echaremos mano esencialmente de dos teorías:

La primera sirve de soporte para comprobar si el proceso de la individualización es una tendencia cada vez mayor en las sociedades complejas (más desarrolladas) y si éstas han exigido la sustitución de un sistema de valores tradicionales por otro sistema más moderno, así como una sustitución de la autoridad tradicional por otra más racional.

Como indicadores para medir la individualización se ha utilizado la batería de las respuestas que identifican de una manera general los grandes espacios de valores en los que se mueven los individuos y que se manifiestan como grandes objetivos en la vida, que se aproximan a los que Rokeach (1973) ha denominado valores finalistas (cf.: Rokeach's Value Survey, RVS, Rokeach, 1979: 1-11). Para lo cual, se ha preguntado a los individuos cuáles son las cualidades que pueden hacer desarrollar a los niños, representando, de este modo, los valores que los individuos consideran esenciales para la vida. De las 11 hipótesis, el individuo podría escoger solamente hasta 5 . Las hipótesis eran las siguientes: buenos modales; independencia; disposición a trabajar duro; sentido de la responsabilidad; imaginación; tolerancia y respeto por los demás; sentido por la economía y espíritu de ahorro; determinación y perseverancia; creencias religiosas; altruismo, no ser egoísta y, finalmente, obediencia. Las respuestas podrían variar entre 0 (no menciona) y 1 (importante). Todas estas hipótesis fueron sometidas a un análisis factorial, 
forzando la construcción de una solución con apenas un factor, de forma a obtener dos ejes diferentes de polarización. Más adelante, se explica el resultado del análisis factorial y los factores que dieron origen al índice de individuación, lo que nos permite diferenciar los valores tradicionales frente a los valores de individuación.

La segunda teoría, elaborada por Ronald Inglehart, afirma que, a partir de la II Guerra Mundial, las sociedades tienden a basarse más en valores de autorrealización y participación (postmaterialistas) que en valores como los de la seguridad económica o de la seguridad ciudadana, o sea valores "de supervivencia" (materialistas).

En lo relativo a las relaciones entre las tesis de la individualización y del materialismopostmaterialismo se parte desde la perspectiva de que el proceso de la modernización (de acuerdo con la conceptualización elaborada por Max Weber) ha conducido a la sustitución de un sistema de valores tradicionales (en que imperaría la autoridad tradicional) a un sistema más moderno de valores seculares (con una autoridad más racional). Esto es, los valores que originaron la modernización y que, consecuentemente, han llevado a la individualización social, fueron los del mérito individual, de "motivación de logro" (McClelland, 1961, Alonso y Fernández Rodríguez, 2013), valores de emancipación, que de alguna forma implican una menor importancia dada a la autoridad y por tanto fueron rechazados por los sistemas de valores religiosos tradicionales.

Como indicadores para medir el materialismo y posmaterialismo se ha preguntado a los entrevistados, entre cuatro objetivos (goals), importantes para su país, cuál era el que en su opinión era más importante como objetivo a alcanzar en los próximos años, y cuál era el segundo más importante.

Los cuatro ítems propuestos eran los siguientes: 1 . Mantener el orden en el país; 2. Dar a la gente más oportunidades de participar en las decisiones políticas importantes; 3 . Combatir la subida de precios; 4. Proteger la libertad de expresión.

Los individuos que han optado por la primera y tercera opción (seguridad física y económica) son clasificados como materialistas; mientras los que han preferido la segunda y la cuarta opción (de pertenencia y libertad intelectual) son interpretados como postmaterialistas. Los que han optado por un ítem materialista y un postmaterialista son caracterizados como mixtos. De este modo, una vez que cada individuo podía seleccionar dos ítems, se han construido seis combinaciones posibles finales: 1 y 3 (materialismo); 2 y 4 (postmaterialismo); 1 y $2 ; 1$ y $4 ; 2$ y 3 o 3 y 4 (mixtos).

\section{RESULTADOS}

Encontrada la pregunta que podría definir la individualización, se prosigue sometiendo la batería de respuestas a un análisis factorial de componentes principales, para verificar que hay dos ejes diferentes de polarización. Para ello utilizamos la rotación Varimax, la cuál minimiza el número de variables que tienen saturaciones altas en cada factor, reforzando la tendencia para que se formen componentes no correlacionados, y forzamos la construcción de una solución con apenas un factor, que nos ayuda a simplificar la comparación entre los 9 casos (8 países más el Conjunto) (cf.: C.1.).

Como es visible en la factorial realizada a partir del Conjunto de los países, tanto en el 90 como en el 2000 , existe una clara polarización de los valores, los cuáles se agregan por un lado en torno a principios tradicionales (puntuaciones negativas), por otro en torno a principios que expresan la individualización (puntuaciones positivas). 
De entre de estos 11 "valores finales", que reflejan los valores de Rokeach, se puede observar que, en el 90, la Obediencia y la Fe son los valores que mejor definen los principios tradicionales frente a la Independencia y a la Determinación, que expresan mejor los valores de individualización. Una década más tarde, a pesar de mantenerse la misma tendencia, los valores que pasan a definir mejor los principios tradicionales son la Obediencia y los Modales, mientras que los valores que mejor identifican la individualización son los mismos que en el 90 (cf.: Cuadro. 1).

\begin{tabular}{|c|c|c|c|c|c|}
\hline & & \multicolumn{2}{|c|}{ Conjunto } & \multicolumn{2}{|c|}{ Portugal } \\
\hline & & 1990 & 2000 & 1990 & 2000 \\
\hline \multirow{5}{*}{ 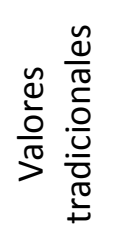 } & Obediencia & $-0,51$ & $-0,55$ & $-0,52$ & $-0,39$ \\
\hline & Fe religiosa & $-0,43$ & $-0,37$ & $-0,43$ & $-0,44$ \\
\hline & Trabajo duro & $-0,40$ & $-0,37$ & $-0,50$ & $-0,26$ \\
\hline & Ahorro & $-0,38$ & $-0,39$ & $-0,51$ & $-0,60$ \\
\hline & Modales & $-0,35$ & $-0,41$ & $-0,45$ & $-0,27$ \\
\hline \multirow{6}{*}{ 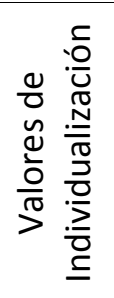 } & Altruismo & 0,11 & 0,08 & 0,28 & 0,29 \\
\hline & Tolerancia & 0,22 & 0,24 & 0,37 & 0,48 \\
\hline & Responsabilidad & 0,34 & 0,39 & 0,36 & 0,53 \\
\hline & Imaginación & 0,45 & 0,42 & 0,38 & 0,02 \\
\hline & Determinación & 0,48 & 0,46 & 0,54 & 0,51 \\
\hline & Independencia & 0,60 & 0,58 & 0,57 & 0,34 \\
\hline
\end{tabular}

Cuadro 1: Análisis Factorial Individualización vs. Tradicionalismo.

Fuente: Elaboración propia a partir de EVS.

Base: Total de la población del Conjunto y de Portugal.

A partir de este análisis factorial, es notoria la presencia de valores que contrastan dos polos distintos, los cuáles definen principios tradicionalistas $y$, por oposición, principios de individualización. Es a partir de estos polos de valores que construiremos nuestro índice de individualización, que tiene por base el principio de la Obediencia y de la Fe Religiosa (valores tradicionales) frente al principio de la Independencia y de la Determinación (valores de la individualización).

De este modo, se ha partido del principio de que es más importante para el niño aprender la "obediencia y la fe religiosa" que la "independencia y determinación"1.

De acuerdo con este mismo método, se ha observado que los países de nuestro estudio presentan diferencias en cuanto a estos valores ${ }^{2}$. Tanto en el 90 como en el 2000, Austria es el país que presenta el mayor grado de individualización (en el 90, con 3,6 y, en el 2000, 3,7 en una escala de 1 a 5 puntos); en el polo opuesto, con valores más tradicionales, se encuentra, en el 90, Polonia $(2,3)$ y, en el 2000 , Polonia y Portugal (2,8 ambos los países) (cf.: Cuadro 2$)$.

Se subraya además que los países se dividen en dos grupos diferentes: por un lado se encuentran los países con valores inferiores a la media de la escala (3): Polonia, Portugal, Irlanda, España e Italia, siendo éstos los países que se identifican más con los valores tradicionalistas; por otro lado, se encuentran los países con valores superiores a la media de la escala: Austria,

\footnotetext{
1 El índice de la individualización se calcula directamente con las variables Fe Religiosa, Obediencia, Independencia y Determinación, siempre que las cuatro tengan respuesta válida. Pudiendo variar entre 1 y 5 , en que los valores más bajos representan mayor tradicionalismo y los más altos indican elevada individualización.

2 En el $90 F(7,13.033)=141,07, p<0,001, \eta^{2}=0,07$; en el $2000 F(7,11.320)=100,98, p<0,001, \eta^{2}=0,06$.
} 
Bélgica, Francia y, en el 2000, Italia, identificándose más con los valores individualistas (cf.: Cuadro 2).

También se puede verificar que, entre el 90 y el 2000, hay una ligera tendencia, en la mayoría de los países, al aumento de la individualización y a la consecuente disminución de los valores tradicionales, salvo España y Portugal que mantienen su grado de individualización (2,9 y 2,8, respectivamente) (cf.: Cuadro 2).

\begin{tabular}{l|cc}
\hline & 1990 & 2000 \\
\hline Austria & $3,6 \mathrm{a}$ & $3,7 \mathrm{a}$ \\
Bélgica & $3,2 \mathrm{~b}$ & $3,3 \mathrm{~b}$ \\
Francia & $3 \mathrm{c}$ & $3,2 \mathrm{~b}$ \\
Irlanda & $2,8 \mathrm{~d}$ & $2,9 \mathrm{c}$ \\
Italia & $2,9 \mathrm{~cd}$ & $3,2 \mathrm{~b}$ \\
Polonia & $2,3 \mathrm{e}$ & $2,8 \mathrm{c}$ \\
España & $2,9 \mathrm{~cd}$ & $2,9 \mathrm{c}$ \\
Portugal & $2,8 \mathrm{~d}$ & $2,8 \mathrm{c}$ \\
\hline Conjunto & 3 & 3,2 \\
\hline
\end{tabular}

Cuadro 2: Índice de Individualización, por país. Fuente: Elaboración propia a partir de EVS. Base: Total de la población por país.

Ya que Portugal se identifica más con valores tradicionales que individualizados, es importante percibir qué grupos de individuos contribuyen más a esta realidad.

Observando los comportamientos de las diferentes generaciones, se verifica que, tanto en el 90 como en el 2000, las generaciones más jóvenes se identifican más con los valores individualizados, frente a las generaciones más viejas que, naturalmente, se presentan como más tradicionales. Esta realidad en el Conjunto de los países presenta diferencias apenas entre los más jóvenes: en cuanto que en el 90 , es la generación de 60 la que se identifica más con los valores individualizados $(3,3)$, en el 2000 , este nivel de individualización pasa a ser identificado con las 3 generaciones más jóvenes (los nacidos entre 1951-81), lo que demuestra que esta diferenciación no se debe a efectos de ciclo de vida sino a efectos generacionales, esto es, la hipótesis generacional remite a la relativa permanencia de las prioridades valorativas en las diferentes generaciones ${ }^{3}$ (cf.: Cuadro 3).

La tendencia al aumento de la individualización, aunque ligera, verificada en el Conjunto entre el 90 y el 2000, no se observa en Portugal, ya que la oscilación de los comportamientos verificada en las diferentes generaciones no demuestra una única tendencia (cf.: Cuadro 3).

Como se aprecia en el cuadro 3., en Portugal no hay diferencias significativas entre hombres y mujeres, en cuanto al grado de individualización. Tanto en el 90 como en el 2000, ambos se identifican más con los valores tradicionales debido a que se encuentran por debajo del grado medio de la escala (3). Mirando al Conjunto, aunque las diferencias son poco expresivas,

\footnotetext{
3 En el $90, F_{\text {Conjunto }}(5,13.033)=144,05, p<0,001, \eta^{2}=0,05 ; F_{\text {Portugal }}(5,1.169)=17,67, p<0,001, \eta^{2}=0,07 ;$ en el 2000, $F_{\text {Conjunto }}$ $(5,11.320)=89,54, p<0,001, \eta^{2}=0,04 ; F_{\text {Portugal }}(5,996)=15,42, p<0,001, \eta^{2}=0,07$.
} 
los hombres y las mujeres del Conjunto se identifican más con los valores individualizados que con los portugueses ${ }^{4}$ (cf.: Cuadro 3).

\begin{tabular}{c|c|cc|cc}
\hline \multicolumn{2}{c|}{} & \multicolumn{2}{c|}{ Portugal } & \multicolumn{2}{c}{ Conjunto } \\
\cline { 3 - 6 } \multicolumn{2}{c}{} & 1990 & 2000 & 1990 & 2000 \\
\hline \multirow{4}{*}{ Cohortes } & $1907-20$ & $2,4 \mathrm{a}$ & $2,4 \mathrm{a}$ & $2,5 \mathrm{a}$ & $2,6 \mathrm{a}$ \\
& $1921-40$ & $2,4 \mathrm{a}$ & $2,5 \mathrm{a}$ & $2,7 \mathrm{~b}$ & $2,8 \mathrm{~b}$ \\
& $1941-50$ & $2,7 \mathrm{ab}$ & $2,8 \mathrm{a}$ & $3 \mathrm{c}$ & $3,2 \mathrm{c}$ \\
& $1951-60$ & $3 \mathrm{bc}$ & $2,9 \mathrm{a}$ & $3,1 \mathrm{~cd}$ & $3,3 \mathrm{c}$ \\
& $1961-70$ & $3 \mathrm{bc}$ & $2,8^{\mathrm{a}}$ & $3,3 \mathrm{~d}$ & $3,3 \mathrm{c}$ \\
& $1971-81$ & $3,3 \mathrm{c}$ & $3,3 \mathrm{~b}$ & $3,2 \mathrm{~d}$ & $3,3 \mathrm{c}$ \\
\hline \multirow{6}{*}{ Sexo } & Hombre & 2,8 & 2,9 & 3,1 & 3,2 \\
& Mujer & 2,7 & 2,7 & 2,9 & 3,1 \\
\hline
\end{tabular}

Cuadro 3: Índice de Individualización, según cohortes generacionales y sexo.

Fuente: Elaboración propia a partir de EVS.

Base: Total de la población del Conjunto y de Portugal.

Pasando a analizar la escala materialismo-postmaterialismo en el Conjunto de los 8 países de nuestro estudio, se verifica que las generaciones más viejas son las que evidencian en mayor escala los valores materialistas (por lo menos hasta la generación nacida en la década de los 40). Esto no es de extrañar puesto que ellas han vivido una época histórico-cultural fuertemente marcada por la inseguridad, proveniente de guerras sucesivas $y$, consecuentemente, por la inestabilidad económica proveniente de todo ese contexto. De la observación de esta realidad, emana y se comprueba la hipótesis a la que Inglehart ha denominado "escasez".

Sobrepasada dicha realidad socio-histórica, las sociedades entraron en un proceso de veloz desarrollo, lo cuál ha conducido a una mayor seguridad tanto física como económica. De ahí que las generaciones más jóvenes (esencialmente a partir de la generación nacida en la década de 50), crecidas en este ambiente - seguras de los bienes esenciales -, asignan otras prioridades, diferentes de las de sus padres, valorando más el bienestar, el ocio, la auto-realización, etc., que no serían más que los valores postmaterialistas. De acuerdo con estos cambios generacionales, se comprueba la hipótesis de la "socialización" (cf.: Gráfico 4).

Tal como nos muestra el Gráfico 4, donde se evidencia los datos del Conjunto, hay claras diferencias en las prioridades valorativas que presentan las generaciones más jóvenes y las más viejas. Esta diferenciación se debe, tal como ya se ha señalado, al diferente contexto en que ambas generaciones se socializan. Con todo, al observar las mismas generaciones en el 90 y en el 2000, se constata un cierto retroceso de los valores postmaterialistas en las generaciones más jóvenes, este hecho se puede deber a la recesión económica que la Unión Europea ha venido sufriendo, lo que podrá estar en el origen de alguna inseguridad o inestabilidad entre las generaciones más jóvenes.

${ }^{4}$ En el $90, T_{\text {Conjunto }}(13.032)=7,72, p<0,001, \eta^{2}=0,01 ; T_{\text {Portugal }}(1.169)=0,37, n s ;$ en el $2000, T_{\text {Conjunto }}(11.317)=3,91, n s ; T_{\text {Portugal }}$ $(996)=3,42, n s$. 


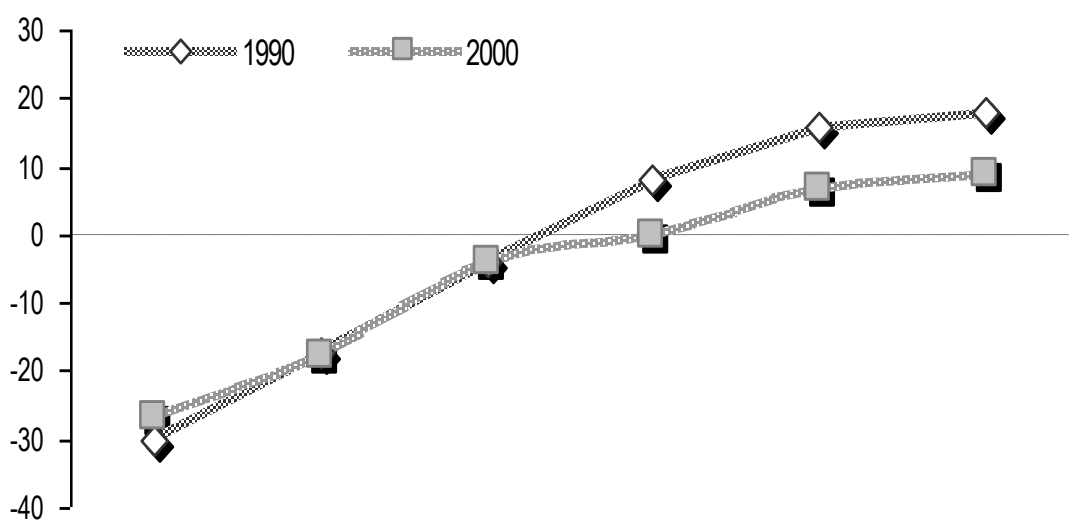

$1907-1920 \quad 1921-1940 \quad 1941-1950 \quad 1951-1960 \quad 1961-1970 \quad 1971-1981$

Gráfico 4: Postmaterialismo, en el Conjunto, según las generaciones (Diferencias de porcentajes) Fuente: Elaboración propia a partir de EVS. Base: Total de la población del Conjunto de los 8 países. Nota: Diferencia entre el porcentaje de postmaterialistas y la de materialistas para cada uno de los 6 grupos generacionales en 1990 y 2000.

Observando esta misma realidad por los países de nuestro estudio, se corrobora, tanto en el 90 como en el 2000, que las generaciones más jóvenes se orientan en mayor medida que las mayores hacia los valores postmaterialistas. En el 90, es entre los individuos nacidos en la década de 40 y 50 donde los valores postmaterialistas superan a los materialistas, salvo en Polonia y en Portugal. En el 2000, tal hecho no se verifica, ya que, en la mayoría de los países, la línea de crecimiento del postmaterialismo baja en casi todas las generaciones, situación que es más evidente en Francia y en Irlanda (sobre todo en las generaciones más jóvenes). Austria e Italia son las únicas excepciones, puesto que ven subir su nivel de postmaterialismo en casi todas las generaciones (cf.: Gráfico 5).

Analizando la situación concreta de Portugal, se observa que, mientras que en el 90 la generación nacida en la década de los 70 apenas presenta valores postmaterialistas superiores a los materialistas, en el 2000 todas las generaciones presentan valores materialistas, lo que hace que Portugal (a excepción de Polonia) se convierta en el país con el mayor porcentaje de individuos materialistas ( $34 \%$ en el 90 y $36 \%$ en el 2000) y, consecuentemente, con menor número de postmaterialistas ( $12 \%$ en el 90 y $10 \%$ en el 2000 ) (cf.: Gráfico 5).

Dicho esto, se manifiesta la notoria diferencia entre la actitud de Portugal y los demás países en la forma en cómo se han interiorizado los valores postmaterialistas. Esta diferencia puede deberse a dos distintas realidades: por un lado, al observar los datos del año 90, sabemos que Portugal no ha seguido el nivel de desarrollo de los demás países, debido a que el alto nivel (alteré el orden de las palabras) del materialismo manifestado traduce la realidad socio- 
económica vivida por los portugueses hasta la década de los 70. Recordemos que Portugal ha vivido en conflicto toda la década de los 60 y parte de los de 70 (guerras coloniales), hecho que no ayuda a la prosperidad de los valores postmaterialistas, una vez que la seguridad física y económica no estaban garantizadas. Tal realidad hace que el crecimiento económico efectivo portugués no siga el desarrollo verificado en los demás países europeos de nuestro contexto cultural. Por otro lado, se observa que la generación más joven, la nacida en la década de los 70 que deja de tener razones para preocuparse de su seguridad (ya que vive en ambiente socializador estable) - inicia un proceso de cambio acelerado hacia valores postmaterialistas, más notable en los años 90 (Duque, 2012). A pesar de esta realidad, se verifica en el 2000, en esta misma generación (la más joven), un retraso en este proceso de cambio, haciendo que todas las generaciones se vuelvan más materialistas que postmaterialistas. Esta realidad puede deberse al hecho de que esta generación - que va a introducirse en el mundo del trabajo y a construir su estructura familiar - será la que más sentirá la inestabilidad económica verificada en la Unión Europea y, consecuentemente, en Portugal (cf. Gráfico 5).

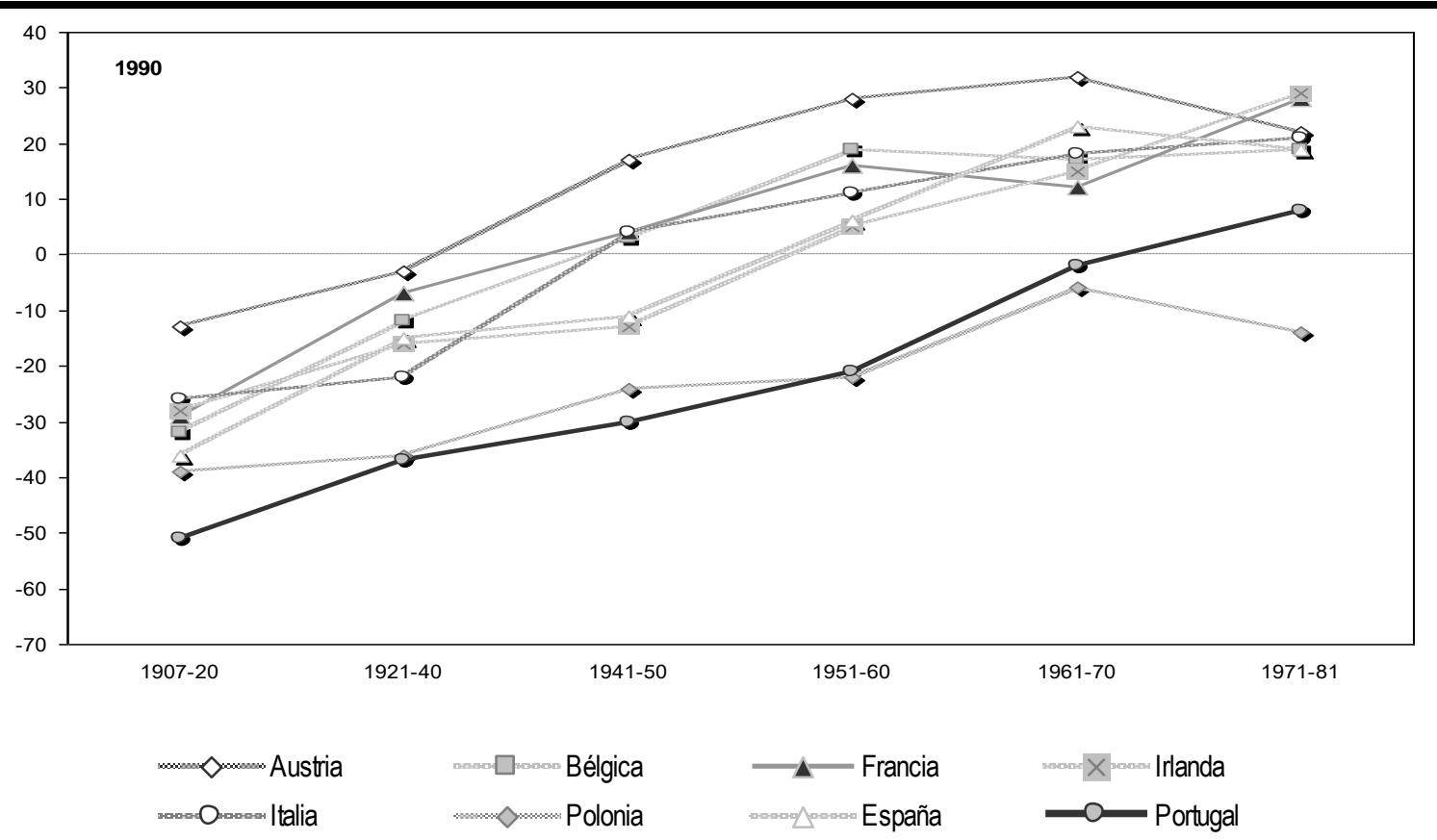

Gráfico 5. Postmaterialismo, por país, según las generaciones (Diferencias de porcentajes) 


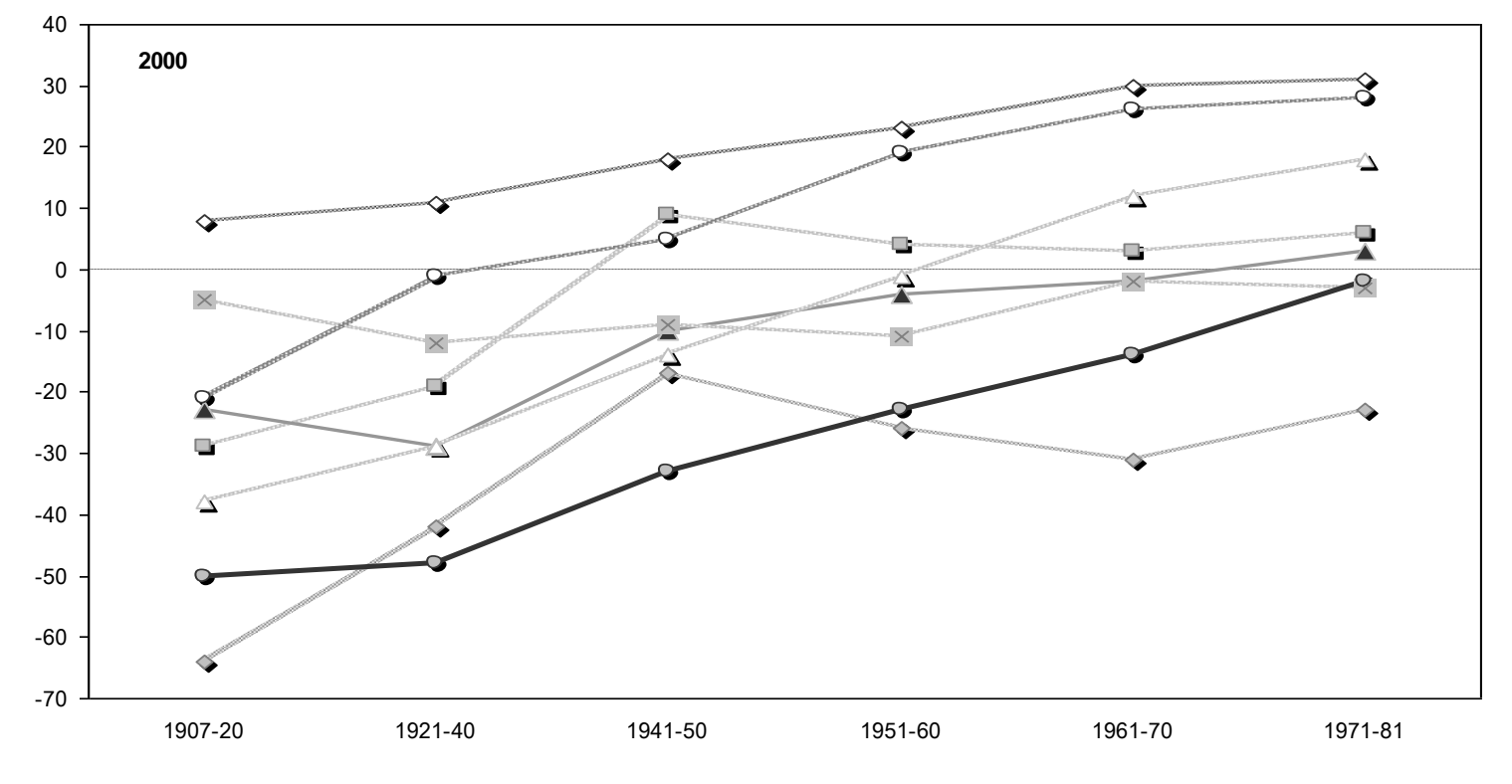

Fuente: Elaboración propia a partir de EVS. Base: Total de la población de los 8 países.

Nota: Diferencia entre el porcentaje de postmaterialistas y de materialistas para cada uno de los 6 grupos generacionales en 1990 y 2000.

Pasemos ahora a analizar la escala de materialismo-postmaterialismo según el sexo del entrevistado. Para esto vamos a utilizar los coeficientes Eta, que ayudarán a medir la magnitud de las diferencias de los promedios de la escala entre distintos grupos ${ }^{5}$.

En el conjunto de los países, las diferencias entre la forma como los hombres y las mujeres se sitúan ante los valores no son muy expresivas, pero, como nos muestran los datos, son significativas, evidenciando que los hombres son más postmaterialistas, salvo en el 90 en Irlanda, en dónde las mujeres aparecen como más postmaterialistas y, en el 2000 en Austria e Irlanda, en donde las mujeres son tan postmaterialistas como los hombres.

A pesar de que en la mayoría de los países las diferencias entre los sexos no sean muy expresivas, hay países en los que esta diferencia se acentúa entre el 90 y el 2000. Entre ellos se encuentran Bélgica y Portugal, siendo éste último el país de los 8 que más diferencias presenta en el período que va del 90 al $2000^{6}$, situándose, con todo, en el 2000 por debajo de las diferencias que se dan entre hombres y mujeres en Austria y Polonia.

El hecho de que se aprecie en Portugal un aumento significativo de las diferencias entre hombres y mujeres en un periodo de 10 años, nos lleva a formular la pregunta acerca de las características peculiares que asumen las diferencias de género en nuestro país y la importancia que tienen ciertos valores para los hombres y las mujeres. No se pretende agotar este interrogante en nuestra investigación, sino más bien plantearla como una tarea de investigación pendiente que puede llevar, por ahora, a reflexionar sobre las políticas de género que el país tiene trazado e implantado

A fin de contrastar la hipótesis vamos a correlacionar los índices de individualización y materialismo-postmaterialismo, una vez que se trata de dos ejes unidimensionales que sirven para medir dimensiones valorativas distintas pero que se completan, caracterizando ambos el

\footnotetext{
5 El Coeficiente de Eta varía entre "0" y "1". Cuanto más próximo al "1" sea su valor, más acentuadas son las diferencias y viceversa.

${ }^{6}$ En el 90 , Portugal presenta un $\eta$ de 0,03 , siendo él país de los 8 que presenta menor diferencia entre hombres y mujeres, todavía, en el 2000 , ésta diferencia es muy acentuada $(\eta=0,10)$, haciendo con que sea el país que, en 10 años, más diferencias manifiesta.
} 
doble proceso de cambio que va desde el materialismo al postmaterialismo y desde los valores tradicionales a los de individualización. Se supone que estos dos ejes, analizados conjuntamente, logran una explicación más completa del cambio social que si fuesen analizados aisladamente.

Entre todos los países, tanto en el 90 como en el 2000, entre el materialismopostmaterialismo e individualización se manifiesta una correlación lineal positiva, lo que traduce que a mayores niveles de postmaterialismo corresponden mayores niveles de individualización y, por oposición, a mayores niveles de materialismo, mayores principios tradicionales (en el Conjunto, en el 90, $r=0,25 \mathrm{y}$, en el 2000, $r=0,23)$, siendo Irlanda, tanto en el 90 como en el 2000 , el país que presenta la correlación más baja $(r=0,18$ y 0,06), frente, en el 90 , a Portugal ( $r$ $=0,31)$ y, en el 2000, Francia $(r=0,30)$, como los países con correlaciones más fuertes ${ }^{7}$.

En un análisis más detallado, observando los datos del gráfico referidos más abajo, se verifica, entre el 90 y el 2000, un aumento de los valores de individualización tanto entre los materialistas como entre los postmaterialistas ${ }^{8}$. Esta tendencia se expresa de forma distinta entre los países: por un lado, se encuentran Bélgica, Francia, Italia y Polonia que ven ascender su nivel de individualización entre los sujetos materialistas, mixtos y postmaterialistas; por otro, Irlanda y Portugal que ven aumentar la individualización entre los materialistas y mixtos, aun así la ven disminuir entre los individuos postmaterialistas (cf.: Gráfico 6).

Portugal es el país de los 8, junto con Polonia, que en el 2000 presenta el grado de individualización más bajo, tanto entre los materialistas y mixtos como entre los individuos postmaterialistas, esto es, los portugueses equilibran sus pautas valorativas y comportamentales tanto entre los principios de la obediencia y la fe religiosa, como entre los principios de la independencia y determinación, sin la inclinación hacia uno de los extremos. Con todo, como se visualiza en los datos gráficos relativos a Portugal, los materialistas se identifican más con los principios tradicionales y los postmaterialistas con los de la individualización ${ }^{9}$ (cf.: Gráfico 6).

Conviene aún subrayar que, a pesar de que Portugal y Polonia se aproximan en cuanto a su grado de individualización, hay una diferencia entre ellos: entre el 90 y el 2000, Polonia ve ascender su nivel de individualización tanto entre los materialistas como en los postmaterialistas, aumentando las diferencias entre éstos; Portugal, a pesar de ver aumentar el nivel de individualización entre los materialistas, ve disminuir ese nivel entre los postmaterialistas y, consecuentemente, reducir las diferencias del grado de individualización entre materialistas y postmaterialistas $^{10}$ (cf.: Gráfico 6).

\begin{tabular}{|c|c|}
\hline Austria & Bélgica \\
\hline 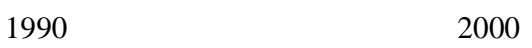 & 1990 \\
\hline
\end{tabular}

\footnotetext{
${ }^{7}$ Correlaciones entre materialismo-postmaterialismo e individualización, en el 90 y en el 2000, por país: Austria $(r=0,21 ; 0,18)$; Bélgica $(r=0,23 ; 0,23)$; Francia $(r=0,21 ; 0,30)$; Irlanda $(r=0,18 ; 0,06)$; Italia $(r=0,24 ; 0,19)$; Polonia $(r=0,14 ; 0,17)$; España $(r=$ $0,21 ; 0,24)$ y Portugal $(r=0,31 ; 0,15)$.

8 Valores promedios en el Conjunto de los países entre materialismo-postmaterialismo e individualización, en el 90 y en el 2000: materialismo $=2,6$ y 2,8 ; mixto $=3$ y 3,2; postmaterialismo $=3,5$ y 3,6, respectivamente.

${ }^{9}$ Valores promedios en Portugal entre materialismo-postmaterialismo e individualización, en el 90 y en el 2000: materialismo $=2,4$ y 2,6; mixto $=2,9$ y 3 ; postmaterialismo $=3,5$ y 3 , respectivamente.

${ }_{10}$ En Portugal, en el $90, F(2,1.092)=56,92, p<0,001, \eta^{2}=0,10$ y, en el 2000, $F(2,950)=14,21, p<0,001, \eta^{2}=0,03$; en el Conjunto $F(2,12.329)=399,54, p<0,001, \eta^{2}=0,06 \mathrm{y}$, en el 2000, $F(2,10.754)=310,63, p<0,001, \eta^{2}=0,06$; en los demás países: Austria, $F_{1990}(2,1.412)=33,67, p<0,001, \eta^{2}=0,05$ y $F_{2000}(2,1.455)=23,54, p<0,001, \eta^{2}=0,03$; Bélgica, $F_{1990}(2$, $2.591)=73,37, p<0,001, \eta^{2}=0,05$ y $F_{2000}(2,1.807)=50,28, p<0,001, \eta^{2}=0,05$; Francia, $F_{1990}(2,960)=22,27, p<0,001, \eta^{2}=$ 0,04 y $F_{2000}(2,1.566)=80,36, p<0,001, \eta^{2}=0,09$; Irlanda, $F_{1990}(2,987)=19,99, p<0,001, \eta^{2}=0,04$ y $F_{2000}(2,971)=2,23, n s$; Italia, $F_{1990}(2,1.949)=62,11, p<0,001, \eta^{2}=0,06$ y $F_{2000}(2,1.882)=34,73, p<0,001, \eta^{2}=0,04$; Polonia, $F_{1990}(2,926)=8,73, p$ $<0,001, \eta^{2}=0,02$ y $F_{2000}(2,1.042)=16,65, p<0,001, \eta^{2}=0,03$; España, $F_{1990}(2,2.403)=57,79, p<0,001, \eta^{2}=0,05$ y $F_{2000}(2$, $1.070)=33,54, p<0,001, \eta^{2}=0,06$.
} 

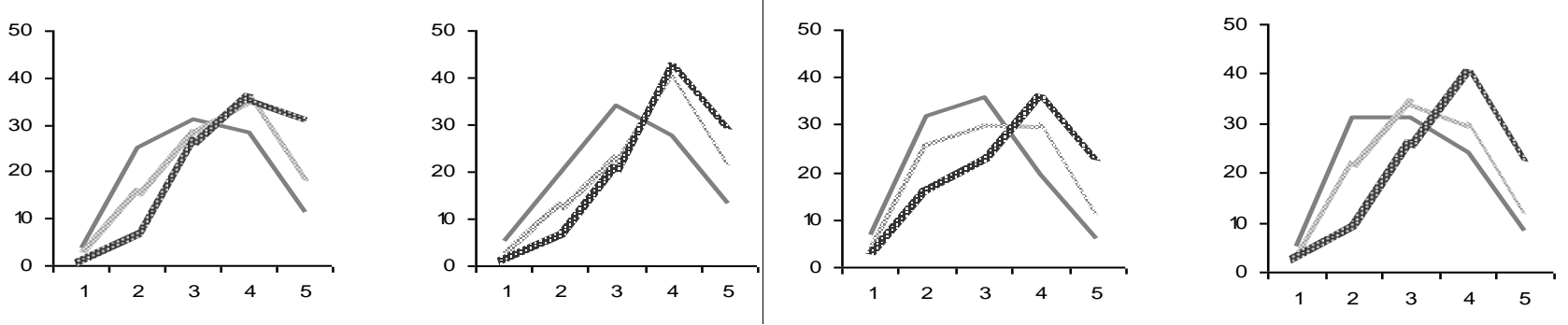

— Materialististas

Mixed

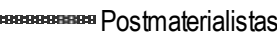

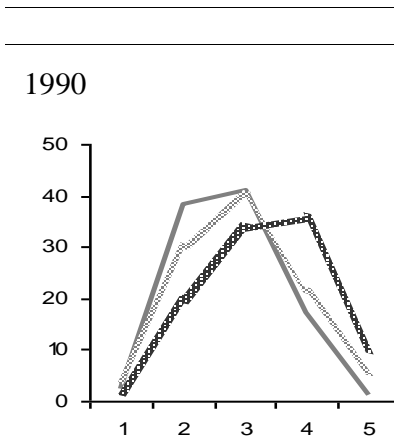

\section{Francia}

2000

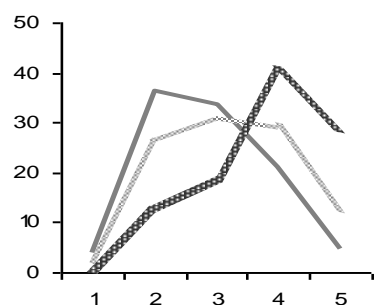

\section{Irlanda}

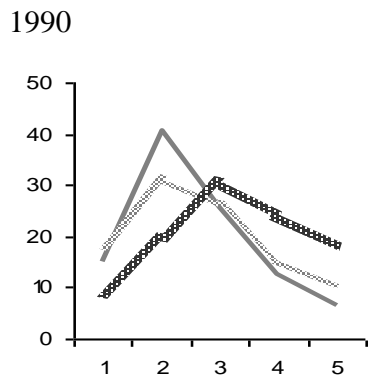

2000

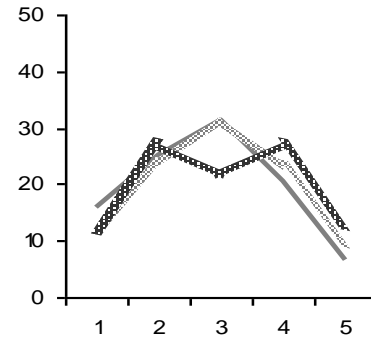

Polonia

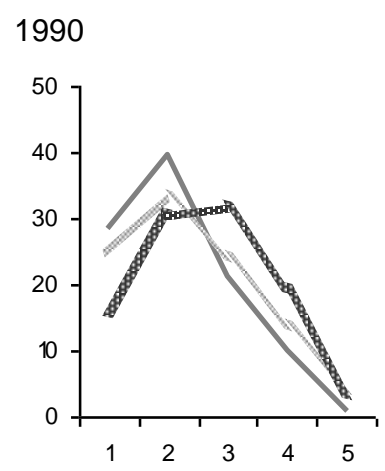

2000

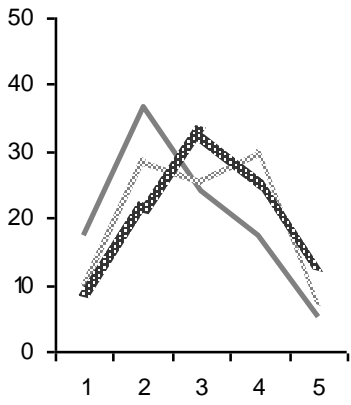

Materialististas

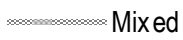

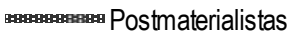

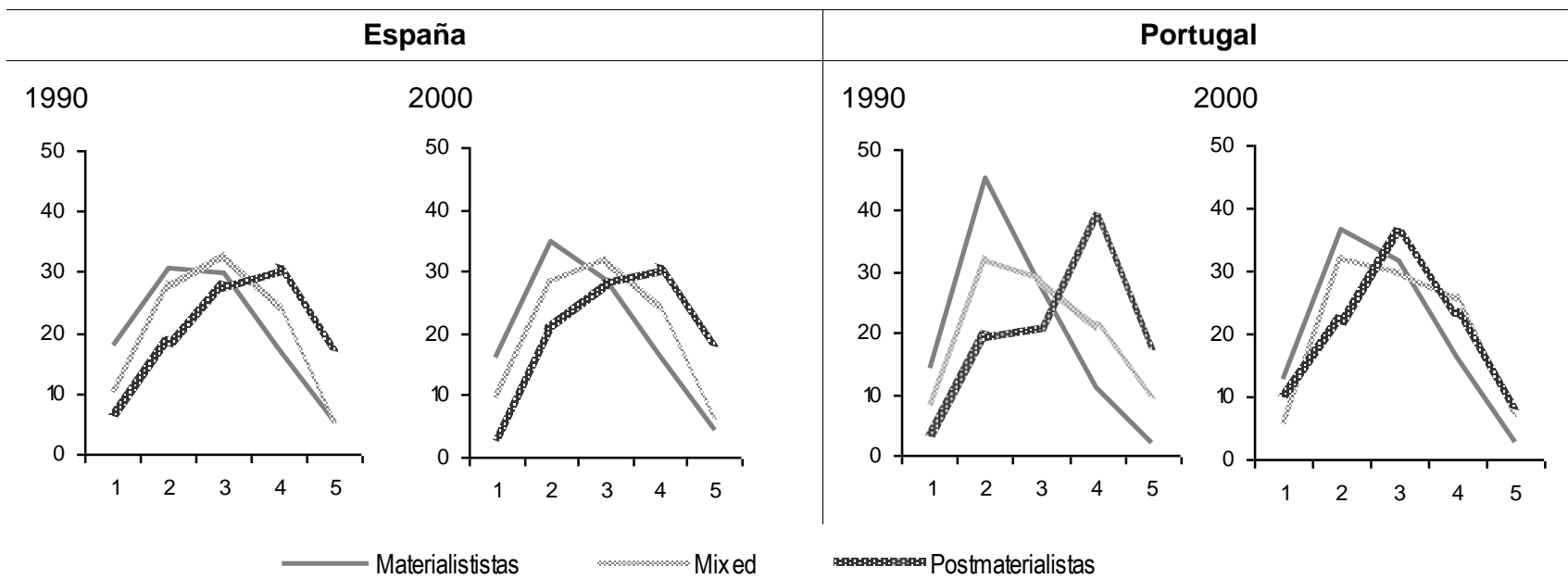




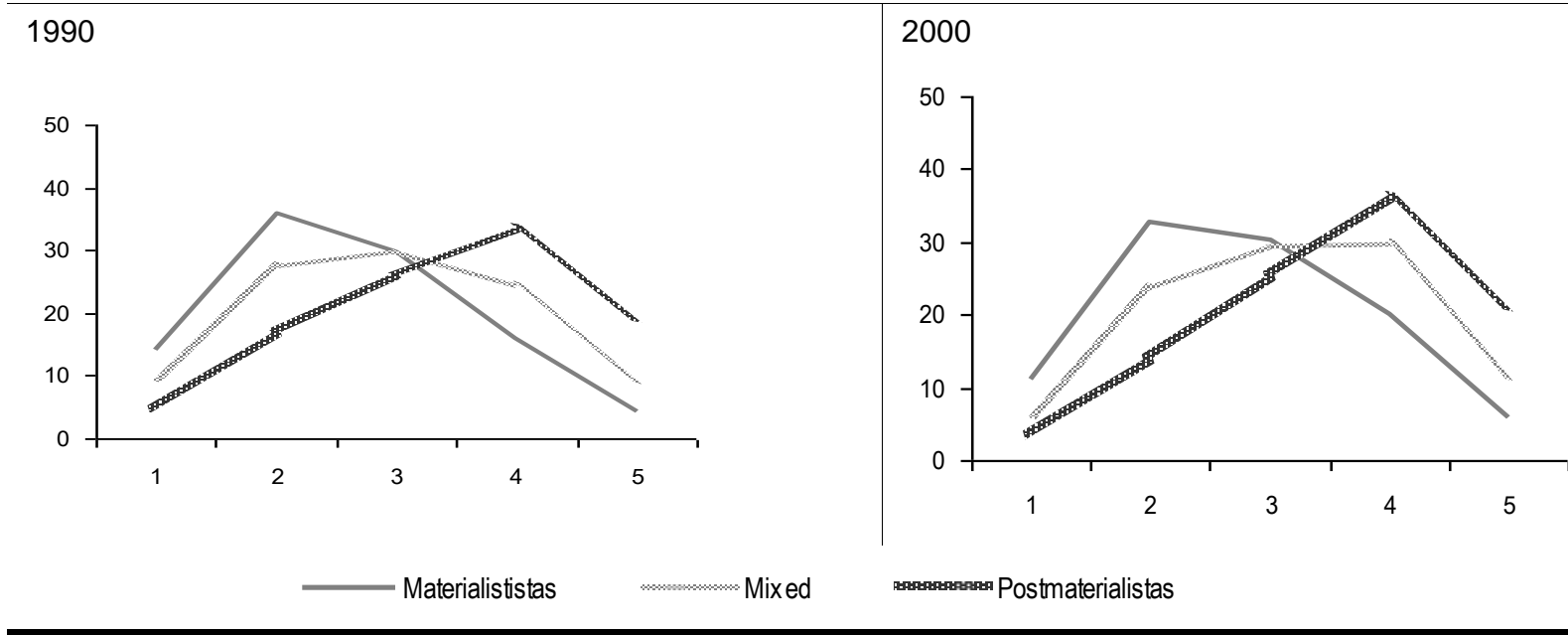

Gráfico 6: Materialismo-postmaterialismo, según la individualización Fuente: Elaboración propia a partir de EVS. Base: Población de cada país y del Conjunto. Nota: Índice de Individualización varía entre 1 (valores tradicionales) y 5 (valores de individualización).

\section{CONCLUSIÓN}

Se ha analizado que en los 8 países hay una tendencia, aunque esta difiera de país a país, al aumento de los valores de individualización, siendo las generaciones más jóvenes las que más se identifican con estos valores. Estos resultados corroboran lo que el Grupo Europeo de Valores, representados por Loek Halman, Peter Ester y Rud De Moor (1994), ya había señalado, cuando afirma que la sociedad está asistiendo a un creciente proceso de individualización.

Además de la individualización, la sociedad moderna experimenta también una ascensión de valores postmaterialistas, centrados más en la autorrealización y la participación.

A través de lo que hemos dicho anteriormente, se corrobora, en todos los países en general y en Portugal en particular, la hipótesis de la "socialización", admitiendo que el cambio de valores hacia una orientación postmaterialista se debe, sobre todo, a un cambio generacional y no al efecto de período. Salvo las excepciones circunstanciales socio-económicas (de alguna recesión) a que ya nos referimos, se verifica, de este modo, un cambio hacia las prioridades valorativas postmaterialistas, que ganan especial relieve entre las generaciones más jóvenes, que son postmaterialistas en mayor proporción que los de edad más alta. Tal hecho es ratificado por las correlaciones negativas entre postmaterialismo y edad, relación que se observa sea cual sea el nivel general de postmaterialismo en una sociedad, que para el caso portugués se verifica en las relaciones negativas y estadísticamente significativas (en el $90, r=-0,26$ y en el $2000, r=-0,28$, para ambos casos $p<0,001$ ).

Se podría, entonces, preguntar, ¿en general son los países de este estudio postmaterialistas? Al analizar los resultados relativos al Conjunto de los países, se verifica que los individuos de nuestro estudio, tanto en el 90 como en el 2000, no presentan mayoritariamente valores postmaterialistas, sino mixtos (en el 90 , eran $56 \%$ y, en el 2000 , suben para el $58 \%$ ), bajando, en el Conjunto, $1 \%$ tanto de materialistas como de postmaterialistas en el mismo período. Se puede decir, además, repasando los países, que hay una disminución de los valores 
postmaterialistas, una vez que, mientras que en el 90 sólo tres países de los ocho presentaban más individuos con valores postmaterialistas que materialistas (Austria, Bélgica y Francia); una década más tarde, en el 2000, sólo Austria e Italia presentan más postmaterialistas que materialistas. Este hecho se puede deber, tal como ya ha sido referido, a la inestabilidad económica y al contexto socio-cultural de inseguridad, que el mundo y concretamente la Unión Europea han vivido en los últimos años.

Dicho esto, se puede concluir que estamos asistiendo a una reconfiguración de la mentalidad que tiene como sujeto determinante las generaciones más jóvenes que asimilaron naturalmente los valores de la independencia y de la determinación - propios de las sociedades individualizadas - y los valores del bienestar y de auto-realización - propios de las sociedades postmaterialistas, una vez que su contexto socio-cultural y económico les fue favorable.

\section{BIBLIOGRAFÍA}

Abramson, P. R., Inglehart, R. (1992). Generational Replacement and Value Change in Eight West European Societies. British Journal of Political Science 22, 2, 183-228.

Adorno, Th., et al. (1973). La disputa del positivismo en la sociología alemana. Barcelona: Grijalbo.

Alonso, L. E. \& Fernández Rodríguez, C. J. (eds.) (2013). Los discursos del presente. Un análisis de los imaginarios sociales contemporâneos. Editorial Siglo XXI.

Beck, U. (1998). La sociedad del riesgo. Barcelona: Paidós.

Beck, U. (2007). Dialécticas de la modernidad: cómo las crisis de la modernidad surgen de los triunfos de la modernidade. Revista Sistema, n. 199, Julio, 3-24.

Beck, U., Giddens, A. \& Lash, S. (1997). Modernización Reflexiva. Política, Tradición y estética en el orden social moderno. Madrid: Alianza.

Berger, P. (1994). Una gloria lejana. La búsqueda de la fe en época de credulidad. Barcelona: Herder.

Bescansa, C. \& Jerez, A. (2011). Dentro y fuera de la Red: Perspectivas Políticas y Generacionales. Investigación cualitativa. Madrid: INJUVE.

Cassirer, E. (1984). Filosofía de la llustración. México: FCE.

Castells, M. (2000). La era de la información. Economía, sociedad y cultura. Vol. I, Madrid: Alianza.

Conover, M., Ferrara, E., Menczer, F. \& Flammini, A. (2013). The Digital Evolution of Occupy Wall Street. PLoS ONE, vol. 8, núm. 5, e64679.

Cotarelo, R. (2013). Ciberpolítica: las nuevas formas de acción y comunicación políticas. Valencia: Tirant Lo Blanch. 
Díez Nicolás, J. (1994). Postmaterialismo y desarrollo económico. In J. Díez Nicolás \& R. Inglehart (Eds), Tendencias mundiales de cambio en los valores sociales y políticos (pp. 125-155). Madrid: Fundesco.

Díez Nicolás, J. (1995). Postmaterialism and the social ecosystem. In B. Setter-Liver (ed.), Culture within nature (pp. 179-189). Basilea: Wiese Publiching.

Duque, E. (2003). A Identidade na pós-modernidade: um conceito histórico-hipotético. Cadernos do Noroeste 21, 1-2: 39-51.

Duque, E. (2012). Contributos para uma crítica da aceleração do tempo. In Araújo, E. \& Duque, E. (eds), Os tempos sociais e o mundo contemporâneo. Um debate para as Ciências Sociais e Humanas (pp. 117-127). Braga: Centro de Estudos de Comunicação e Sociedade.

Duque, E. (2013). Work Values in Portuguese Society and in Europe. In A. P. Marques, Gonçalves, C. \& Veloso, L. (coord.), Trabalho, organizações e profissões: recomposições conceptuais e desafios empíricos (pp. 81-98). Braga: Universidade do Minho, Associação Portuguesa de Sociologia.

Durán Vázquez, J. F. y Duque, E. (2017). Culturas y generaciones. Actitudes y valores hacia la educación, el trabajo y el consumo en tres generaciones de jóvenes españoles. Aposta. Revista de Ciencias Sociales, 72, 129-165.

Escobar, A. (2012). Una minga para el postdesarrollo: Lugar, medio ambiente y movimientos sociales en las transformaciones globales. Bogotá: Desde Abajo.

Ester, P., Halman, L., De Moor, R. (1994). The Individualizing Society: Value Change in Europe and North America. Tilburg: Tilburg University Press.

Habermas, J. (1988). La lógica de las ciencias sociales. Madrid: Tecnos.

Habermas, J. (1989). El discurso filosófico de la modernidad. Madrid: Taurus.

Habermas, J. (1991). Escritos sobre moralidad y eticidad. Buenos Aires: Paidós.

Habermas, J. (1999). Teoría de la Acción Comunicativa II. Crítica de la razón funcionalista. Buenos Aires: Taurus.

Halman, L. (1995). Is there a Moral Decline? A Cross-National Inquiry into Morality in Contemporary Society. International Social Sciences Journal 145, 419-439.

Halman, L. (2003). Capital Social na Europa Contemporâne. In J. Vala, M. V. Cabral \& A. Ramos (eds), Valores Sociais: Mudanças e Contrastes em Portugal e na Europa (pp. 257-292). Lisboa: Imprensa de Ciências Sociais.

Heidegger, M. (1967). El ser y el tiempo. México: F.C.E.

Homans, G. (1991). El conductismo y después del conductismo. In Giddens, A. Sociología Hoy. Madrid: Alianza.

Houellebecq, M. (1999). Partículas elementales. Barcelona: Anagrama.

Imbert, G. (2011). La tribu informática identidades y máscaras en Internet. Revista estudios de juventud, n. 92 (Adolescentes Digitales), 123-131.

Inglehart, R. (1971). The Silent Revolution in Europe: Intergenerational change in post-industrial societies. American Political Sciences Review 65, 991-1017.

Inglehart, R. (1976). The Nature of Value Change in Post-Industrial Societies. In L. Lindberg (ed.) Politics and the Future of Industrial Society. New York: McKay.

Inglehart, R. (1977). The Silent Revolution: Changing Values and Political Stylus among Western Publics. Princeton: Princeton University Press.

Inglehart, R. (1985). New perspective on value change. Comparative Political Studies 17, 485-532. Inglehart, R. (1990). Culture Shift. Princeton: Princeton University Press.

Inglehart, R. (1997). Modernization and Postmodernization. Princeton: Princeton University.

Lipovetsky, G. (1983). A Era do Vazio. Lisboa: Gallimard. 
Lyotard, J. F. (1983). La Condition Postmoderne: Rapport sur le Savoir. Paris: Les Editions de Minuit.

Mardones, J. M. (1998). El discurso religioso de la modernidad. Habermas y la religión. México: Anthropos.

Maslow, A. H. (1954). Motivation and Personality. Nueva York: Hasper and Row.

Mc Carthy, Th. (1998). La teoría crítica de Jurgen Habermas. Madrid: Tecnos.

Mcclelland, D. (1961). The achieving society. Princenton: Van Nostrand.

Nevitte, N. y Cochrane, C. (2006). Individualization in Europe and America: Connecting Religious and Moral Values. In Y. Esmer \& T. Pettersson (eds), Measuring and Mapping Cultures: 25 Years of Comparative Values Surveys. Leiden and Boston: Brill.

Orizo, A. \& Elzo, J. (2000). España 2000, entre localismo y la globalidad. Madrid: Universidad de Deusto/Ediciones SM.

Ortega y Gasset, J. (1981). Historia como sistema. Madrid: Revista de Occidente en Alianza Editorial.

Osorio G. \& Sergio, N. (2015). Epistemología axiológica y conocimiento transdisciplinar. Estrategias cognoscitivas para el reconocimiento y cultivo de la cualidad humana profunda y la dimensión sagrada de la existência. Revista Horizonte, Belo Horizonte, vol. 13, no. 37, 213252.

Prensky, M. (2011). Enseñar a nativos digitales. Madrid: SM.

Quintanilla, M. A. (1981). A favor de la razón. Ensayos de filosofía moral. №. 5. Madrid: Taurus.

Roales-Nieto J. G. (2009). Cambio social y cambio personal. Estudio preliminar del cambio en valores en una muestra intergeneracional. International Journal of Psychology and Psychological Therapy, 9, 395-420.

Roales-Nieto J. G. \& Segura A. (2010). Intergenerational differences in materialism and postmaterialism values in a Spanish simple. International Journal of Psychology and Psychological Therapy, 10, 499-512.

Rokeach, M. (1973). The Nature of Human Values. Nueva York: The Free Press.

Rokeach, M. (1979). Understanding human values: Individual and societal. New York: Free Press.

Rorty, R. (1984). Habermas and Lyotard on Post-modernity. Praxis Internacional 4, 1, 32-44.

Sichirollo, L. (1976). Dialéctica. Barcelona: Labor.

Touraine, A. (1998). ¿'Podemos vivir juntos? México: FCE.

Vala, J. (1993). Valores sócio-políticos. In L. França (ccord.), Portugal, Valores Europeus, Identidade Cultural. Lisboa: Instituto de Estudos para o Desenvolvimento.

Vattimo, G. \& Rovatti, P. A. (coord.), (1983). El pensamiento débil. Madrid: Cátedra.

Weber, M. (1964). Economía e sociedad. Esbozo de sociología comprensiva. México: F.C.E.

Weber, M. (1974). La ética protestante y el espíritu del capitalismo. Buenos Aires: Bartolomé U. Chiesino.

Weber, M. (1983). Ensayos sobre Sociología de la Religión. Vol. I, Madrid: Taurus. 